NBER WORKING PAPER SERIES

INCENTIVE EFFECTS OF PENSIONS

Edward P. Lazear

Working Paper No. 1126

NATIONAL BUREAU OF ECONOMIC RESEARCH

1050 Massachusetts Avenue

Cambridge MÁ 02138

May 1983

The research reported here is part of the NBER's research program in Pensions and in Labor Studies. Any opinions expressed are those of the author and not those of the National Bureau of Economic Research. 


\begin{abstract}
$\underline{\text { Abstract }}$
Many different types of pension plans exist in American firms. The stipulations of plans vary dramatically, even among large firms, with respect to vesting, relationship of the pension to final salary, maximum and minimum years of service constraints, and maximum and minimum benefit levels. These provisions are examined to determine their effects on worker behavior. Specifically, the paper analyzes which plans encourage or discourage appropriate worker responses in hours worked, turnover, human capital investment and effort. An attempt is made to explain the provisions in light of the findings.
\end{abstract}

Edward P. Lazear Graduate School of Business University of Chicago 1101 East 58th Street Chicago, I11inois 60637

(312) $962-7464$ 
Private pensions have experienced rapid growth during the past 30 years. Although there are elements of pensions that many plans share, there are also a large number of differences across plans. The most obvious differences relate to the basic structure of the pension benefit formula: the plan may be of the defined contribution or of the defined benefit type. In the latter catesory the flat or pattern plan can be distinguished from the formula or convent onal plan.

Economists often refer casually to the effects that changes in the benefit formulas have on worker behavior. Most frequently, these comments relate to the effects of vesting on worker turnover. But as far as I am aware, no systematic attempt has been made to analyze the ways in which various provisions of the pension benefit formulas influence worker behavior. ${ }^{1}$ This essay attempts to do just that. Specifically, it examines the effects of pension benefit provisions on worker turnover, labor supply, investment in human capital, and worker effort. Existing benefit formulas are compared with formulas that produce first best results and an attempt is made to determine if and understand why provisions may deviate from those that produce efficient outcomes. In so doing, it is hoped that the understanding of the existence of private pensions will be furthered.

The paper examines a number of different pension institutions. It analyzes how worker productivity (as affected by turnover, investment in human capital and effort) is influenced by a change from defined benefit to defined contribution plans and why pattern plans and conventional plans induce very different behavior. It also examines the effects of minimum and maximum years of service requirements, industry-wide vs. company-wide plans, the relationship between hours-of-work constraints and pensions, why pensions are often related to final salary, as well as a number of other issues. For most of the 
analysis, the pension rule is taken to be exogenous so that the incentive effects of that rule per se can be described. This is a less ambitious task than understanding why those rules exist and what other factors are involved. Occasionally some conjectures on the reasons for particular rules are presented, but that is not the primary purpose of the essay. The most important findings are:

Pension benefit formulas cannot affect worker behavior or cause deviations from efficiency if each worker's wage is directly and appropriately related to his own pension level. Without explicit offsets, the following results obtain:

- Defined benefit pattern plans induce an efficient allocation of resources.

- Defined benefit conventional plans induce too little turnover, too much work, too much effort and too much human capital investment relative to the efficient outcome.

- Defined contribution plans always induce an efficient allocation of resources.

- Complete and immediate vesting is a necessary condition for fully efficient pension plans. Incomplete vesting. tends to result in too little work by some, and too much by others. The standard intuition that pensions create longer job tenure on average is not necessarily correct. The apparent inefficiency, but widespread existence, of imperfectly vested pension plans suggests that the sorting or retention of workers may be an important problem.

- Minimum years of service constraints create inefficiency in pattern plans, whereas such constraints may actually reduce the inefficiency of conventional plans. Further, maximum years of service constraints 
tend to offset the inefficiency introduced by minimum years of service constraints.

- The inefficiencies introduced by defined benefit conventional plans can be undone by specifying required effort levels. Thus, piece rate workers, who choose their own effort levels, should not have defined benefit conventional plans.

\section{$\underline{\text { A Model }}$}

The essence of the relationship between benefit formulas and worker behavior can be analyzed in the context of a one-period model. Workers are paid some wage, $W$, and are entitled to a pension, $P$, which may depend upon years of service, salary, and a number of other rules having to do with minimum and maximum age and years of service. In this one-period context, "years of service" is thought of simply as the number of years or hours, $\mathrm{H}$, worked during the period so that a benefit formula that depends upon years of service is one that has $\mathrm{H}$ as an argument.

Workers can control two variables: The amount of time worked, $H$, is the labor supply variable and is affected by the worker's alternative use of time function, $L(H)$. This reflects either the value of leisure or the wage on an alternative job, whichever is highest. In this way, we can analyze worker turnover in this simple framework since there need be no formal distinction between retirement and quitting to take another job (although the pension flow may differ depending upon what the worker does with his time).

Both effort and investment in human capital are captured by the worker's control over $K$, which affects worker productivity and potentially the wage. No distinction is made in this model between effort and human capital, although some differences may be relevant. 2 There is some cost associated 
with increasing $K$, given by the total cost function $C(K)$. This carries either the interpretation of costs of investment in human capital, in the form of formal schooling or on-the-job training which occurs before the current period, or the disutility value associated with additional effort. The reason that $\mathrm{H}$ and $\mathrm{K}$ must be distinguished is that effort or investment in human capital affects pensions in a different way from years of service. All defined benefit plans depend upon years of service, but only some depend upon salary as well. Effort and human capital investment are likely to affect salary directly, but years of service only indirectly. The approach does not build in any explicit reason for the existence of pensions, although a number have been given in the literature. ${ }^{3}$ Instead, the reverse strategy is adopted. The effects of various provisions are analyzed in hope of obtaining clues to the reasons for their existence.

Given the two choice variables, it is trivial to write down the efficiency conditions for labor supply, H, and effort or human capital, $\mathrm{K}$. The value of $K$ in increasing output is normalized to be $\$ 1$ and the worker's productivity at $\bar{K}=\hat{0}$ is $V$ per unit of time. Thus, the worker's output is $(\mathrm{V}+\mathrm{K}) \mathrm{H}$ and the efficiency criterion is derived by maximization of social benefit minus social cost or, under separability, by$$
\operatorname{Max}(V+K) H-C(K)-I(H) \text {. }
$$

$\mathrm{H}, \mathrm{K}$

The first-order conditions for efficiency are

$$
\mathrm{H}=\mathrm{C}^{\prime}(\mathrm{K})
$$

and

$$
V+K=L^{\prime}(H)
$$


Whether the worker behaves in a way so as to insure efficiency depends upon his own utility maximization. Additionally, since firms wish to maximize profits, it is necessary to look to the interaction between the two in order to derive implications for changes in the pension plan.

For generality, allow that the worker's choice of $\mathrm{K}$ and $\mathrm{H}$ can affect both $W$ and $P$. Then the worker's problem is

$$
\operatorname{Max}_{H, K} W(K, H) H+P(K, H)-C(K)-L(H)
$$

which yields as first-order conditions,

$$
\partial / \partial H=(\partial W / \partial H) H+W+\partial P / \partial H-L^{\prime}(H)=0 \text {. }
$$

What makes the issue less than straightforward is the fact that payments that takes the form of a pension must be offset by a decrease in the wage rate. This is the result of the firm's zero profit constraint, which is

$$
(\mathrm{V}+\mathrm{K}) \mathrm{H}=\mathrm{WH}+\mathrm{P}
$$

or

$$
\mathrm{W}=\mathrm{V}+\mathrm{K}-\mathrm{P} / \mathrm{H}
$$

Equation (3) says that total payments to the worker must equal total output by the worker.

Important is the way in which the worker perceives that his wage is affected by his pension. Although it is true that (3) must hold for all workers, it is not necessary that the worker's wage respond directly to his own pension level. For example, a wage could be "fixed," and the worker could be allowed to choose his pension by altering $H$, but these actions would not affect $W$ as he perceives it. Although it is true that for all workers (3) 
must hold, any one worker's effect on $w$ may be regarded as trivial or zero. First, consider the opposite situation, where the worker recognizes that any increase in $P$ that is not accompanied by a corresponding increase in productivity must result in a lower wage. (This would be true in a one-worker firm.) The result is that the provisions of the pension plan cannot affect behavior. There is never a deviation from first-best efficiency. The reason is that the worker internalizes the full extent of his actions, no matter how inefficient the pension formula may appear. This is trivial to show formally: If the worker recognizes that (3) holds, then his maximization problem from (2) becomes

$$
\operatorname{Max}_{H, K}(V+K-P / H) H+P-C(K)-L(H)
$$

or

$$
\operatorname{Max}_{H, K}(V+K) H-C(K)-L(H)
$$

which is the same as (1). The first order condition must be the same, viz.,

$$
\text { or } \begin{aligned}
\frac{\partial}{\partial K}=H-\frac{\partial P}{\partial K} & +\frac{\partial P}{\partial K}-C^{\prime}(K)=0 \\
H & =C^{\prime}(K)
\end{aligned}
$$

and

$$
\text { or } \begin{aligned}
\frac{\partial}{\partial H}=V+ & K-\frac{\partial P}{\partial H}+\frac{\partial P}{\partial H}-L^{\prime}(H)=0 \\
V & +K=I^{\prime}(H) .
\end{aligned}
$$

Equations $(4 i, 4 i i)$ are identical to $(1 i, 1 i i)$ so the worker chooses ( $B, K$ ) so as to guarantee first best efficiency, irrespective of the pension benefit formula. Any action: that. the worker takes that affects his pension also affects his wage in the opposite direction and by a corresponding amount. If the worker is fully aware of this, then all pension changes are offset and 
internalized, no matter how bizarre the pension formula. It is the recognition by the worker that things must add up on the firm side of the problem that forces him to behave efficiently.

There is another way to state the same proposition: Distortions caused by the pension can always be undone by a judiciously chosen wage function. As long as

$$
W(K, H) \equiv V+K-P(K, H) / H \quad \text { for all } K, H
$$

the worker's behavior cannot be affected by the pension. Whatever effect $K$ and $\mathrm{H}$ have to increase $\mathrm{P}$ is exactly offset by a reduction in $\mathrm{W}($ ). As long as the worker understands tinis relationship, pension effects wash out. Then how can pension formulas affect behavior? In a multi-worker firm, it may well be the case that the individual's wage is not a direct function of his own pension benefits, even though all must add up across workers. This has nothing to do with worker heterogeneity, but is the result of an externality that is produced by separating the wage determination process from the pension determination process at the level of the individual worker. Two points are worth noting: First, there is no obvious reason why the firm doesn't make the worker explicitly aware of the true relationship between $P$ and $w$. This is explored below. Second, a difference between the defined benefit and defined contribution plans may be that the latter makes explicit the relationship between $P$ and $W$ whereas the former does not. This is also discussed below.

Those points aside, consider the worker's problem when $\overline{P / H}$ is set so that in equilibrium $\overline{\mathrm{P} / \mathrm{H}}=\mathrm{V}+\mathrm{K}-\mathrm{P}\left(\mathrm{H}^{*}, \mathrm{~K}^{*}\right) / \mathrm{H}^{*}$ where $\mathrm{H}^{*}, \mathrm{~K}^{*}$ are the result of the worker's maximization problem, which takes $\overline{\mathrm{P} / \mathrm{H}}$ as constant. This insures zero profits, but the worker does not take that condition into account in choosing $\mathrm{H}, \mathrm{K}$. For most of what follows, it is useful to recognize that 
pension benefit formulas rarely $y^{4}$ directly depend upon $k$, but instead depend upon $K$ indirectly through $W$. Therefore let $P=P(W, H)$ for the remainder. Further, suppose for simplicity that $\mathrm{W}$ is independent of $\mathrm{H}$. If workers take $\overline{\mathrm{P} / \mathrm{H}}$ as given, then the worker's maximization problem is

where 5

$\operatorname{Max} W(K) H+P(W, H)-L(H)-C(K)$

$\mathrm{H}, \mathrm{K}$

$$
\mathrm{W}(\mathrm{K})=\mathrm{V}+\mathrm{K}-\overline{\mathrm{P} / \mathrm{H}}
$$

The first-order conditions are:

$$
\begin{gathered}
\frac{\partial}{\partial K}=H+\frac{\partial P}{\partial W}-C^{\prime}(K)=0 \\
\frac{\partial}{\partial H}=V+K-(\overline{P / H})+\frac{\partial P}{\partial H}-L^{\prime}(H)=0 .
\end{gathered}
$$

The difference between $(5 i, 5 i i)$ and $(4 i, 4 i i)$ is that in (4), the individual recognizes that increases in $P$ are offset by decreases in $w$. In (5), W is unaffected, as far as the individual worker is concerned, by changes in $P$.

Even if the worker does not take into account the effect of pension on wage, it is not necessarily the case that pensions result in an inefficient allocation of effort, human capital, turnover, and leisure. This is easily seen by examining the maximization problem in (2). In order for efficient outcomes to result, it is sufficient that (2i) reduce to (1i) and (2ii) to (2i). The first condition is met iff

$$
\frac{\partial P}{\partial K}=H\left(1-\frac{\partial W}{\partial K}\right)
$$

and the second condition is met iff

$$
\frac{\partial P}{\partial H}=V+K-W-H \frac{\partial W}{\partial H} .
$$


Any pension-wage relationship that the worker perceives as satisfying

(6a) and (6b) induces an efficient allocation of resources.

When the worker internalizes the firm's side of the problem, he knows that (3) holds or that

$$
P=(V+K-W) H
$$

Differentiating (3) yields

$$
\frac{\partial P}{\partial K}=H\left(1-\frac{\partial W}{\partial K}\right)
$$

so that (6a) is satisfied and

$$
\frac{\partial P}{\partial H}=V+K-W-H \frac{\partial W}{\partial H}
$$

so that (6b) holds. Thus, internalization of (3) results in full efficiency.

Some Implications

Pattern Plans:

Although complete internalization is sufficient for efficiency, it is not necessary. The standard defined benefit pattern plan, where the pension depends only upon years of service and not salary, induces an efficient allocation of resources. That pension takes the form

$$
\mathbf{P}=\mathrm{BH}
$$

where $B$ is a fixed dollar amount and $H$ is chosen by the worker. Under those circumstances, and retaining the assumption that $W=V+K-\bar{P} / \mathrm{H}$, $\partial \mathrm{W} / \partial \mathrm{K}=1$ and $\partial \mathrm{P} / \partial \mathrm{K}=0$ so that $(2 i)$ becomes

$$
H-C^{\prime}(K)=0 \text {. }
$$

Also, $\partial W / \partial H=0$ and $\partial \mathrm{P} / \partial \mathrm{H}=\beta$ so (2ii) becomes 
(7ii)

$$
\text { or } \quad \begin{array}{ll}
W+B-I^{\prime}(H)=0 \\
V+K-I^{\prime}(H)=0
\end{array}
$$

since

$$
\begin{aligned}
\mathrm{w} & =\mathrm{V}+\mathrm{K}-\overline{\mathrm{P} / \mathrm{H}} \\
& =\mathrm{V}+\mathrm{K}-\mathrm{B} .
\end{aligned}
$$

Thus, (7i) and (7ii) are identical to (1i, 1ii) so efficiency is achieved. stated alternatively, since $\frac{\partial P}{\partial K}=0$ and $\frac{\partial W}{\partial K}=1$, (6a) holds. Also, since $\frac{\partial P}{\partial H}=B, \frac{\partial W}{\partial H}=0$, and $W=V+K-\beta,(6 b)$ reduces to $B=B$ and holds as well.

This yields the conclusion that all standard pattern plans are efficient. The reason is that even though the worker does not explicitly take into account that his wage is reduced by an amount corresponding to pension size, he does implicitly. Since the increase in pension value is a function only of time worked, as is earnings, all is implicitly internalized. The worker's "true" annual wage is $\mathrm{W}+\partial \mathrm{P} / \partial \mathrm{H}$. When the pension formula is $\beta \mathrm{H}$, his true wage

$$
\begin{aligned}
& =W+B \\
& =V+K-\overline{P / H}-B \\
& =V+K-B \bar{H} / \bar{H}-B \\
& =V+K
\end{aligned}
$$

so the worker's true wage, as he sees it, is equal to his value to the firm. Thus, all is efficient.

Conventional Plans:

The conventional defined benefit plan, where the pension benefit depends upon some salary average times a factor times years worked does not result in 
an efficient allocation of resources if the worker does not take (3) into account explicitly. This can easily be shown:

The conventional plan has the form

$$
\mathbf{P}=\gamma \mathrm{HW}
$$

so that

$$
\frac{\partial P}{\partial H}=\gamma\left(W+H \frac{\partial W}{\partial H}\right)
$$

and

$$
\frac{\partial P}{\partial K}=\frac{\partial P}{\partial W} \cdot \frac{\partial W}{\partial K}=\gamma H
$$

since

$$
\mathrm{W}=\mathrm{V}+\mathrm{K}-\overline{\mathrm{P} / \mathrm{H}} \text {. }
$$

(The worker takes $\mathrm{P} / \mathrm{H}$ as given at $\overline{\mathrm{P} / \mathrm{H}}$ and $\mathrm{W}$ is independent of $\mathrm{H}$ ). Thus, $\frac{\partial P}{\partial K}=\mathrm{H}$, but $\partial \mathrm{W} / \partial \mathrm{K}=1$ so $\gamma \mathrm{H} \neq \mathrm{H}(1-\partial \mathrm{W} / \partial \mathrm{K})$ unless $\gamma=0$ and (6a) is violated. However, $\partial \mathrm{P} / \partial \mathrm{H}=\mathrm{W}$ and $\mathrm{V}+\mathrm{K}-\mathrm{W}-\mathrm{H}(\partial \mathrm{W} / \Phi \mathrm{H})=\gamma \mathrm{W}$ since $\frac{\partial W}{\partial H}=0$ and $W=\frac{V+K}{1+\gamma}$ because $P / H=W$. Thus, $(6 \mathrm{~b})$ holds. Thus, (2i) does not become (1i) even though (2ii) does become (1ii) for conventional plans. Explicitly, for the conventional plan, first-order conditions are:

$$
\begin{array}{cc}
H(1+\gamma)-C^{\prime}(K)=0 \\
\text { or } \quad H=C^{\prime}(K) /(1+\gamma) \\
V+K-\gamma W+Y^{\prime}-I^{\prime}(H)=0 \\
\text { or } \quad K=L^{\prime}(H)-V .
\end{array}
$$


If the conventional plan results in inefficient effort and labor supply, which way do the effects go? The answer can be easily seen in Figure 1. First-order conditions (1i) and (1ii) are shown by the solid lines, and ( $8 i$ ) is shown by the dotted line. (Recall that ( $8 i i$ ) is identical to (1i)..) Point $Q$ is the solution to $(1 i, 1 i i)$ and also to $(7 i, 7 i i)$ corresponding to the pattern plan since pattern plans are efficient. Point $R$ is the solution to $(8 i, 8 i i)$. Since $Y>0$, the line corresponding to (8i) must lie below that to (1i) which implies that $\mathrm{H}_{\mathrm{C}}>\mathrm{B}^{*}$ and that $\mathrm{K}_{\mathrm{C}}>\mathrm{K}^{*}$. There is too much investment in human capital and effort, and too much labor supply with too little turnover.

Thus, the simplest form of pattern plan provides incentives for an efficient allocation of resources, whereas the standard conventional plan does not. This suggests that conventional plans will also carry other provisions that seek to undo the inefficiencies inherent in these plans. Hours constraints, maximum and minimum numbers of years of service, and other restrictions can be imposed to restore some of the lost efficiency and these are explored in a later section.

It is interesting to perform some comparitive statics to predict when inefficiencies will be most pronounced.

The most obvious relationship is that inefficiency is increased the larger is $\gamma$. Since the current specification of the conventional plan is a one-parameter one, this simply says that the inefficiency is increased the larger is the pension for any given number of hours worked and wage level. This is hardly surprising since if $\gamma$ were zero, there would be no pension and no inefficiency. Given the shapes of the functions, however, an increase in $\gamma$ causes more inefficiency increase in $K$ than it does in H. $^{6}$ 
The inefficiency is greater when the value of raw labor, $v$, is large. Mechanically, this is because the $K=I^{\prime}(H)-V$ function shifts to the northwest. Intuitively, it is because the higher is $v$, the larger is the number of hours worked, even when all is efficient. Thus, the absolute size of the inefficiency increases with $v$. This is more than a neutral change in units, however, because the $C(R)$ function is not permitted to change simultaneously.

Contrast this with the effect of a steepening of the cost function described by an increase in $C^{\prime}(R)$ at every $R$. This has the interpretation of an increase in the disutility of effort or an increase in the cost of improving skills. The effect is similar to a decrease in $\gamma$. It reduces the size of the inefficiency, and does so to a greater extent for $K$ (effort and human capital) than for $H$. The intuition here seems straightforward. Steepening the cost function dampens the inefficiency effect because it makes it more costly to behave in an opportunistic fashion.

The story is analogous for the disutility of hours worked function. An increase in $L^{\prime}(H)$ for all $\bar{H}$ flattens the $K$ function and results in $a$ reduction in both $K$ and $H$. The reduction, however, is proportional so that only the absolute size of the inefficiency decreases.

An obvious question is, "why are conventional plans widespread if they introduce inefficiency?" There are a few possibilities:

First, everything said has been in terms of real wages, rather than nominal ones. A conventional plan that bases the pension on the final few years' salary indexes benefits to inflation. But even in an inflationary environment, the same potential for distortion of too large $H$ and $K$ exists. Further, pattern plans are often indexed to inflation, although usually on an ad hoc basis. All that is necessary is that $B$, the dollar 
amount per year of service, be adjusted to the CPI or other easily obtainable index.

There are other possibilities. It has been assumed throughout that the wage takes the form

$$
W=V+K-\overline{P / H}
$$

As mentioned at the outset, it is always possible to undo the distortion introduced by the pension by changing the wage function in a corresponding fashion. But in this case the way by which the wage function changes to restore optimality is of particular interest because it implies a direct relationship between wages, human capital, and the pension formula.

It turns out that the efficient wage function that also guarantees zero profit is

$$
w=\left(\frac{1}{1+\gamma}\right)(v+K)
$$

That efficiency is guaranteed is easily seen. Equation ( 6 a) becomes

$$
\gamma\left(\frac{1}{1+\gamma}\right) \mathrm{H}=\mathrm{H}\left(1-\frac{1}{1+\gamma}\right)
$$

or

$$
\frac{\gamma}{1+\gamma}=\frac{\gamma}{1+\gamma}
$$

and $(6 b)$ becomes

$$
\begin{aligned}
\gamma & =v+k-w \\
w(1+\gamma) & =v+K \\
w & =\left(\frac{1}{1+\gamma}\right)(v+K) .
\end{aligned}
$$

Since both (6a) and (6b) are true, efficiency is guaranteed. Further, since

$$
W+P / H=W(1+Y)
$$


and since $W=\left(\frac{1}{1+\gamma}\right)(V+K), W+P / H=V+K$ so zero profits are guaranteed.

Thus, $W=\left(\frac{1}{1+\gamma}\right)(V+K)$ is the efficiency inducing wage to couple with conventional defined benefit plans. This is a specific example of the earlier statement that setting

$$
\mathrm{W} \equiv \mathrm{V}+\mathrm{K}-\mathrm{P}(\mathrm{W}, \mathrm{H}) / \mathrm{H}
$$

always insures efficiency. In this case, that identity holds when $W \equiv \frac{1}{H \gamma}(V+K)$.

This produces an implication. The efficient wage function for a pattern plan is

$$
W=V+K-B
$$

and

$$
W=\left(\frac{1}{1+\gamma}\right)(V+K)
$$

for a conventional plan so that, other things equal, wages should rise more rapidly with $\mathrm{K}$ for pattern plan workers than for conventional plan workers. As a corollary, conventional plans with large values of $\gamma$ should reward effort and human capital less well.

These implications are somewhat difficult to test because $K$ is not easily observed. However, since $K$ reflects human capital investment as well as effort, one possibility is to examine the effect of schooling and experience on wages. If wages and pensions are set to induce efficiency, then workers on jobs with conventional plans with high $\gamma^{\prime}$ s should have the lowest effect of schooling and experience on earnings. This will be tested in subsequent work. 
Agaln, no rationale for setting up conventional, as opposed to pattern, plans is built into the analysis. The obvious explanation is that making the pension a function of salary allows one formula to be used for many different worker types. But most companies distinguish between worker types anyway, assigning conventional plans to white collar workers and pattern plans to blue collar workers. Many make finer distinctions. Tying pension to wage in order to conserve on paper seems to be a weak explanation.

The argument that pensions are linked to wages for incentive reasons is not correct. There are two related reasons: First, the wage itself is sufficient to provide the appropriate incentives. Second, too much incentive is generated by tying pension to wage. That was the first result of this section. More subtle explanations are required.

Defined Contribution Plans:

What has been shown so far is that conventional defined benefit plans result in inefficiencies when the worker's wage is not adjusted to his own pension receipt. With defined contribution plans, what the worker receives is equal (in an actuarial sense) to what he contributes. Thus, defined contribution plans cannot introduce inefficiencies, irrespective of their provisions. This is simply a trivial restatement of the proposition that if the worker takes into account that his wage offsets any pension benefits received, he will always internalize the full effects of the pension and behave efficient1y. Writing this down rigorously, note that with the defined contribution pension plan, the contribution per period of time, $G(W, H)$, times the length of working life, $H$, must equal the received pension benefit, $P(W, H)$. In the absence of pensions, the wage must be set equal to $V+x$ in order to achieve efficiency. This follows directly from necessary condition 
(6b) because in the absence of a pension, $\partial \mathrm{P} / \partial \mathrm{H}=0$. Thus, start by setting $\mathrm{W}=\mathrm{V}+\mathrm{K}$ and then introduce a defined contribution plan that taxes $G(W, H)$ per $H$ worked. The worker's problem is then

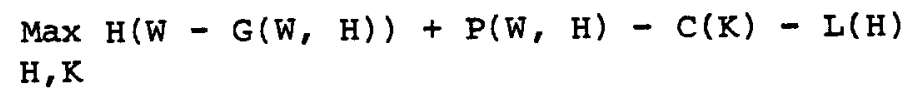

But since the rules of the plan imply that $P(W, H)=H G(W, H),(9)$ becomes

$$
\underset{H, K}{\operatorname{Max}} W H-C(K)-I(H)
$$

or

$$
\operatorname{Max}_{H, K}(V+K) H-C(K)-L(H)
$$

This is identical to (1) so that efficiency is guaranteed. The first-order conditions are

$$
\begin{aligned}
& \frac{\partial}{\partial K}=\frac{\partial W}{\partial K} H-C^{\prime}(K)=0 \\
& \frac{\partial}{\partial H}=W-L^{\prime}(H)=0 .
\end{aligned}
$$

Since $\partial W / \partial R=1,(9 i)$ reduces to $(1 i)$. Further since $P=[G(W, H)] H, W=$ $V+K$ from (3). Since $\overline{P / H}=G(9 i i)$ reduces to (1ii).

Thus, defined contribution plans are always efficient without any required additional constraints. This suggests the implication that defined contribution plans should be more prevalent in situations where the inefficiencies associated with the conventional defined contribution plan are most pronounced. Using the comparative statics results generated above, defined contribution plans should be used over conventional plans when pensions are relatively large ( $\gamma$ causes greater inefficiency), when investment in human capital is high ( $C(K)$ function is flat) and when hours worked are large $(L(H)$ function is flat). This suggests the use of defined contribution plans for high wage, highly skilled workers. 7 
Vesting

In order to consider the effects of vesting, it is necessary to allow for some workers to leave before the vesting date and others to stay beyond that date. The easiest way to do this is to allow for two types of Individuals: the first type has alternative use of time function $L(H)$ and the second has alternative use of time function $\tilde{I}(H)$ such that $\tilde{L}(H)>I(H)$ for all $H$. Let $\lambda$ of the population be of the first type and $(1-\lambda)$ be of the second type.

A full and immediate vesting pension of the pattern plan type is always efficient. This simply requires duplication of the analysis on pp. 9 and 10 above for the two types of workers because implicit in that analysis was the assumption that pensions vest immediately. The first-order conditions of the worker's maximization problem are

$$
\begin{aligned}
H & =C^{\prime}(K) \\
V+K-B+B & =L^{\prime}(H)
\end{aligned}
$$

for the first type, and

$$
\begin{aligned}
\tilde{H} & =C^{\prime}(X) \\
V+X-B+B & =\tilde{L} \cdot(\tilde{H})
\end{aligned}
$$

for the second type.

Now consider the same pattern plans without vesting. The simplest form of nonvesting is to assume that $B=0$ if $H<\bar{H}$. There are three cases: First, $\mathrm{H}<\overline{\mathrm{H}}$ and $\dot{\mathrm{H}}<\overline{\mathrm{H}}$. This is the same as no pension since $\overline{\mathrm{P} / \mathrm{H}}=0$ and so there is full efficiency. Second, $\mathrm{H}>\overline{\mathrm{H}}$ and $\overline{\mathrm{H}}>\overline{\mathrm{H}}$. This is the case just analyzed as fully vested pension benefits and it yields efficiency as well. The only interesting case arises when $\mathrm{H}<\overline{\mathrm{H}}, \tilde{\mathrm{H}} \geq \overline{\mathrm{H}}$ or when $\mathrm{H} \geq \overline{\mathrm{H}}, \tilde{\mathrm{H}}<\overline{\mathrm{H}}$. 
The important feature is that there is subsidization of the stayers by the leavers and this causes a distortion. The wage paid to workers must be sufficiently low to cover the pension costs to $\lambda$ of the population who are stayers. Thus, the zero profit condition is

$$
\lambda(W H+B H)+(1-\lambda) \tilde{W H}=(V+K)(\lambda H+(1-\lambda) \tilde{H})
$$

or

$$
W=V+K-\frac{\lambda \beta}{\lambda+(1-\lambda) \frac{\tilde{H}}{H}} \cdot
$$

Now, the maximization problem for the stayers is

$\left(10^{\prime}\right)$

$$
\operatorname{Max}_{\mathrm{K}, \mathrm{H}} \mathrm{H}\left[\mathrm{V}+\mathrm{K}-\left(\frac{\lambda \beta}{\lambda+(1-\lambda) \frac{\tilde{H}^{*}}{\mathrm{H}^{*}}}\right)\right]+B \mathrm{H}-\mathrm{C}(\mathrm{K})-\mathrm{H}(\mathrm{H})
$$

where stars denote equilibrium values. The first-order conditions are:

$\left(10^{\prime} i\right)$

$$
\frac{\partial}{\partial K}=H-C^{\prime}(K)=0
$$

and

(10 i i i)

$$
\frac{\partial}{\partial H}=V+K+\frac{(1-\lambda) B}{\lambda+(1-\lambda) \frac{\tilde{H}^{*}}{H^{*}}}-I^{\prime}(H)=0 .
$$

Similarly, for leavers,

$\left(10^{\circ}\right)$

$$
\underset{\tilde{\mathbf{K}}, \tilde{\mathrm{H}}}{\operatorname{Max}} \mathrm{H}\left[\mathrm{V}+\tilde{\mathrm{K}}-\left(\frac{\lambda \beta}{\lambda+(1-\lambda) \frac{\tilde{H^{\star}}}{\mathrm{H}^{\star}}}\right)\right]-C(\tilde{\mathrm{K}})-\tilde{\mathrm{I}}(\tilde{\mathrm{H}})
$$

since $\tilde{\mathrm{H}}<\overline{\mathrm{H}}$ so pension $=0$. The first-order conditions are $(10 \tilde{})$

$$
\frac{\partial}{\partial \tilde{K}}=\tilde{H}-C^{\prime}(\tilde{K})=0
$$

and

(10̃ii)

$$
\frac{\partial}{\partial \tilde{\mathrm{H}}}=\mathrm{V}+\tilde{\mathrm{K}}-\frac{\lambda \beta}{\lambda+(1-\lambda) \frac{\tilde{\mathrm{H}}^{*}}{\mathrm{H}^{\star}}}-\tilde{\mathrm{I}} \cdot(\tilde{\mathrm{H}})=0 .
$$


The situation is shown in Figure 2.

points $Q$ and $\tilde{Q}$ are the efficient points for movers and stayers, respectively, and are obtained in the absence of a pension. Note that $H>\tilde{H}$ and $K>\tilde{K}$ because $I^{\prime}(H)<\tilde{I}(H)$ for all $H$.

In the presence of the pension that does not vest immediately, (10'i) and $\left(1 \tilde{0}^{\prime} i\right)$ are identical to $(10 i)$, but $\left(10^{\prime} i i\right)$ and $\left(10^{\prime} i i\right)$ shift as shown in Figure 2. Thus, the new equilibrium points are $R$ and $\tilde{R}$ for movers and stayers.

The most important result is that both $H$ and $K$ deviate from the efficient levels. Stayers spend too much time on the job and invest in too much human capital and effort because the marginal return to a year worked,

$$
V+K+\frac{B(1-\lambda)}{\lambda+(1-\lambda) \frac{\tilde{H}^{*}}{H^{*}}}
$$

exceeds the true value of work, $v+k$. Similarly, leavers leave too early and do not invest in enough human capital and effort because the marginal return to a year worked,

$\mathrm{V}+\tilde{\mathrm{K}}-\frac{\lambda \beta}{\lambda+(1-\lambda) \frac{\tilde{\tilde{H}^{\star}}}{\mathrm{H}^{\star}}}$

is less than the true value of work, $v+\tilde{K}$.

A few additional points are in order. First, average tenure in the economy may rise or fall with the addition of an imperfect vesting provision. Although average tenure rises for those who eventually receive a pension, average tenure falls for those who do not. The effect on the average for the economy as a whole depends upon the proportion of people in each group and upon the increase and decrease for the respective groups, which depends in turn upon the slopes of $L(H)$ and $\tilde{L}(H)$. But it is indeed quite possible that average tenure falls as the result of vesting. 
Second, although it has not been the approach of this analysis to determine why or whether particular provisions exist in long run equilibrium, ignoring those issues is particularly bothersome here. In particular, since leavers subsidize stayers, one would expect some firms to cater only to leavers, offering no pension and paying wage $w=V+K$. This type of selfsorting, akin to Salop and Salop (1976), causes the non-fully vested pension equilibrium to become efficient. The reason is that firms that offer pensions obtain only stayers: Thus $\lambda=1$ and $\left(10^{\prime} i i\right)$ become identical with $(10 i i) .^{8}$

A sorting equilibrium is not established if workers do not know to which class they belong before joining the firm. of course, as is the case with any of these apparent distortions, a firm that offered compensation that induced efficiency could provide higher average wealth to the workers and should attract the entire labor force. So full and immediate vesting should dominate. But if $L(H)$ is positively sloped, then some specificity to the firm-worker relationship is implied. Sorting is particularly important when there exist substantial hiring costs or large amounts of firm-specific capital. Still, there is no obvious reason why a pension is used instead of deferred compensation that takes the form of steeply rising tenure-earnings profiles.

These deeper issues aside, the point is that plans that do not vest immediately introduce distortions. Thus, other things constant, fully-vested plans are more efficient, which implies that plans should be organized at the industry, or better national level to eliminate such distortions. The fact that they are not suggests that some other issue, and the sorting of workers is a logical candidate, raises important problems with which labor markets must grapple. 
The analysis for conventional plans is similar, has the same implications, and is not repeated here.

\section{Minimum Benefit Levels}

A number of plans have minimum benefit levels, below which pension payments are not permitted to fall. These provisions are almost exclusively a characteristic of conventional defined benefit plans. It might be thought that this lump sum feature of the plan is a way by which the inefficiency associated with conventional plans is eliminated. This is not the case.

A conventional plan with a minimum level of benefits takes the form

$$
\begin{aligned}
P & =\text { WH } & & \text { for } P>\underline{P} \\
& =\underline{P} & & \text { otherwise. }
\end{aligned}
$$

Efficiency requires that $(6 a)$ and $(6 b)$ hold. When $P<\underline{P}$, then $(6 a)$ holds because $\frac{\partial P}{\partial K}=0$. But $(6 b)$ is violated because $\frac{\partial P}{\partial H}=0$ and $\underline{P}>0$ implies that $w<v+K$.

If the equilibrium were such that $P>\underline{P}$, then (6a) implies that

$$
\begin{aligned}
\gamma \mathrm{H} & =\mathrm{H}(1-1) \\
& =0 .
\end{aligned}
$$

This can only hold if $\gamma=0$, i.e., if there is no pension so efficiency is not achieved here either. Therefore, the addition of a minimum benefit level cannot restore efficiency.

Minimum and Maximum Years of Service for Pension Accrual

Some plans have minimum service requirements. Pension benefits do not accrue for years worked less than, say, five so that a typical pattern plan formula is 


$$
\begin{aligned}
P & =B(H-\underline{H}) & & \text { for } H>\underline{H} \\
& =0 & & \text { otherwise }
\end{aligned}
$$

Others have maximum years of service allowances so that the pension formula is

$$
\begin{array}{ll}
P=B H & \text { for } H<\bar{H} \\
P=B \bar{H} & \text { otherwise. }
\end{array}
$$

Some plans have both. This section examines the effects of these constraints on behavior. The generalized pattern plan takes the form:

$$
\begin{array}{ll}
P=0 & \text { for } H<\underline{H} \\
P=B(H-\underline{H}) & \text { for } \underline{H}<H<\bar{H} \\
P=B(\bar{H}-\underline{H}) & \text { for } H>\underline{H}
\end{array}
$$

and the generalized conventional plan is

$$
\begin{array}{ll}
P=\gamma(H-\underline{H}) W & \text { for } \underline{H}<H<\bar{H} \\
P=\gamma(\bar{H}-\underline{H}) W & \text { for } H>\bar{H} \\
P=0 & \text { for } H<\underline{H} .
\end{array}
$$

The result is that if the equilibrium level of hours, $H$, exceeds $\bar{H}$ then there is too little $\mathrm{K}$ and $\mathrm{H}$ relative to the efficient amount. If $\mathrm{H}$ $<\mathrm{H}<\overline{\mathrm{H}}$, then there is too much $\mathrm{K}, \mathrm{H}$. If $\mathrm{H}<\underline{\mathrm{H}}$, then all is efficient. The analysis is most straightforward for pattern or flat benefit plans. Here, (2i) remains as in the efficient case (1i), $H-C^{\prime}(K)=0$, but (2ii) becomes

$$
K=I^{\prime}(H)-V \quad \text { for } H<\underline{H}
$$

$$
\begin{array}{cc}
K=L^{\prime}(H)-V-\frac{B \underline{H}}{H} & \text { for } \underline{H}<H<\bar{H} \\
K=L^{\prime}(H)-V+\frac{B(\bar{H}-\underline{H})}{H} \text { for } H>\bar{H} .
\end{array}
$$


Again a graph helps to understand the solution. \& denotes the efficient point in Figure 3.

If $\mathrm{H}<\underline{\mathrm{H}}$, then the constraint is binding for all workers and no one receives pensions. The marginal value of hours in the creation of pension benefits and the average cost of pension benefits is zero so this reverts to the no pension case and all is efficient.

If the relationships are such that the equilibrium has $\underline{H}<H<\overline{\mathrm{H}}$, then the relevant function is $K=L^{\prime}(H)-V-B H / H$ and the equilibrium is at $F_{q}$. Here, $\mathrm{K}_{1}>\mathrm{K}^{*}$, and $\mathrm{H}_{1}>\mathrm{H}^{*}$, so there is too much effort, human capital, and labor supplied. The reason is that when $\overline{\mathrm{H}}>\mathrm{H}>\underline{\mathrm{H}}$, the marginal return to an additional year worked in increasing the pension is $B$. But the cost of the pension earned for only $\mathrm{H}-\underline{\mathrm{H}}$ years is spread over all years $\mathrm{H}$ so that wage is reduced by less than the marginal value of pension benefits. Thus, the net value of an additional hour worked is positive so workers overachieve, and over-achievement depends directly upon the level of $\underline{H}$. The larger is $\underline{H}$, subject to $\mathrm{H}>\underline{\mathrm{H}}$, the larger is the inefficiency. The reverse is true when $\mathrm{H}>\overline{\mathrm{H}}$. Then the marginal pension value of an additional year of work is zero, but the cost of previous accruals is spread over all years so that $\mathrm{W}$ is reduced without an offsetting marginal benefit. Thus, workers under-achieve. This is shown at $\mathrm{F}_{2}$ with $\mathrm{H}_{2}<\mathrm{H}^{*}$ and $\mathrm{K}_{2}<\mathrm{K}^{*}$.

The analysis for conventional plans is similar, but slightly more complicated. Here, (2i) is altered as well, depending upon the regime, since $\partial P / \partial w$ is not generally equal to zero. Instead, 


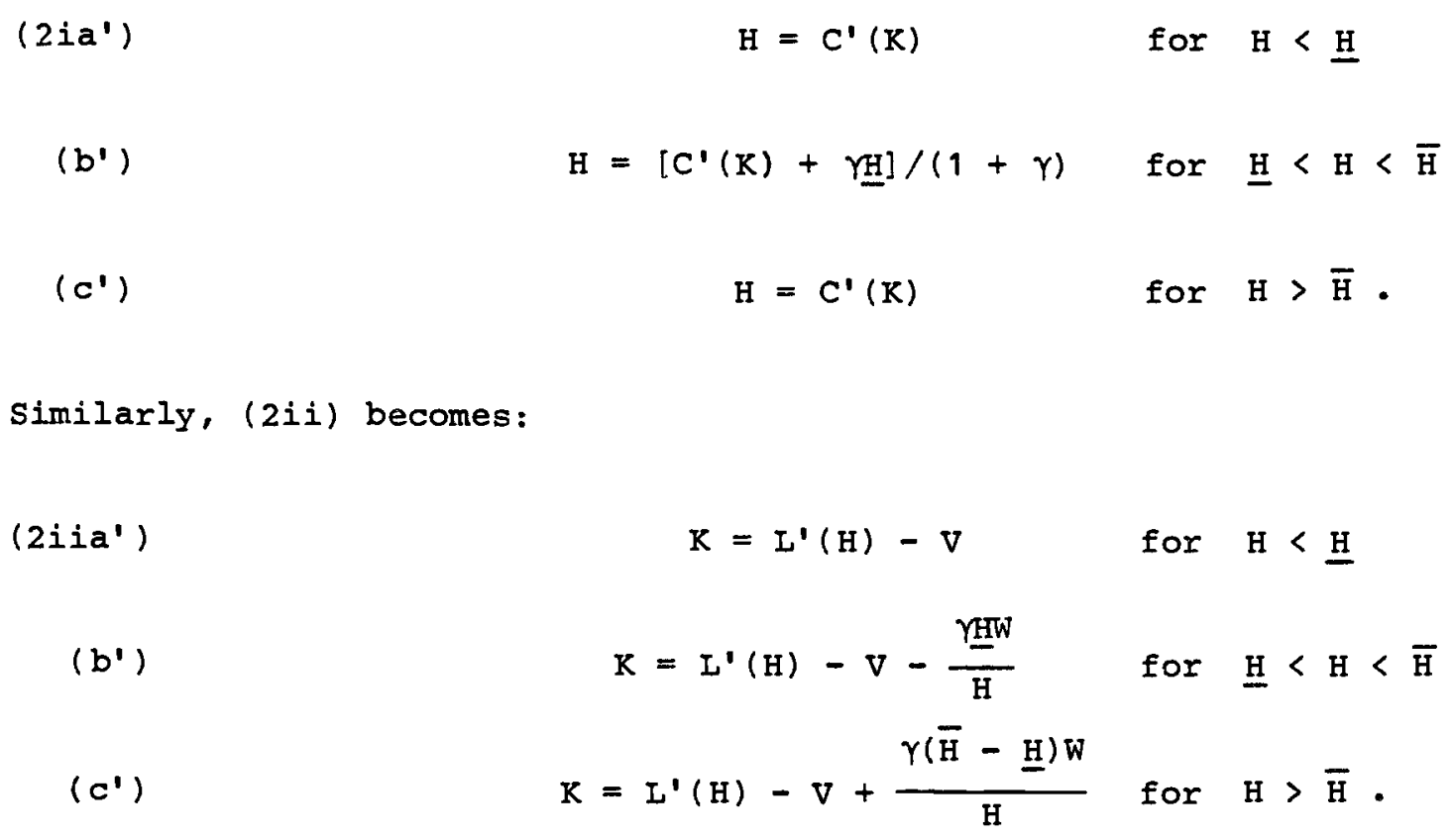

Figures 4 and 5 graph the possibilities.

Figure 4 illustrates the cases where $H<\underline{H}$ and $\underline{H}<H<\bar{H}$. Efficiency is shown at $Q$. If $\underline{H}_{0}$ is sufficiently high so that $H<\underline{H}_{0}$, then $Q$ is the equilibrium and all is efficient. No one works long enough to receive a pension so it drops out completely and all is efficient.

If $\underline{H}_{i}$ is sufficiently low so that $\underline{H}_{1}<H<\bar{H}$ in equilibrium, then the relevant conditions are (2ib') and (2iib'). Equation (2ib') is shown. But since $W$ is a function of $H$, the exact shape of (2iib') is unknown. Still, it is clear that (2iib') lies to the northwest of $K=I^{\prime}(H)-V$. Point $C$ denotes the solution to the standard conventional plan with $\mathrm{H}>\mathrm{H}^{*}, \mathrm{~K}>\mathrm{K}^{*}$. The solution with $\underline{H}>0$ occurs at $D$. $D$ can lie almost anywhere with respect to $Q$ and $C$, so nothing can be said about the efficiency of $D$ relative to $C$. But it is clear that at $D, H>H^{*}$ and $K>K^{*}$ so the inefficiency is never eliminated. In the case of pattern plans, larger deviations of $\underline{H}$ from zero make things worse for both $H$ and $K$ relative to the efficient values. This suggests the following empirical proposition: minimum years of service constraints should never be a feature of pattern 
plans, but sometimes will make things better in a conventional plan and therefore may be part of conventional plans.

Finally, in Figure 5, if $\mathrm{H}>\overline{\mathrm{H}}$ then it must be the case that $\mathrm{H}<\mathrm{H}^{*}$, $K<K^{*}$ because the equilibrium, $E$, must lie to the southwest of the efficient point (since (2iic') lies below $K=I^{\prime}(H)-V$ ). However, whether this is an improvement upon the conventional plan solution at $F$ is ambiguous. It is clear that it reduces $\mathrm{K}$ and $\mathrm{H}$, but by too much. This implies that too little investment, effort and work occur because the marginal incentives are too low as in the flat case. Further, the inefficiency worsens, the larger is $\overline{\mathrm{H}}-\underline{\mathrm{H}}$ so that the existence of a maximum years of service constraint, when binding, should be coupled with minimum years of service constraints.

\section{Constraints on Work Time and Effort}

Suppose that "all-or-nothing" contracts could be offered to workers. The general rule is that these contracts can always be made efficient because they remove ali chance of opportunistic behavior by the worker. In this context, this would amount to a contract that specified $\mathrm{H}=\mathrm{H}^{*}, \mathrm{~K}=\mathrm{K}^{*}$ and some lump sum payment. Ignoring costs of monitoring and enforcement, it is useful to ask whether, when and what kind of constraints are desirable. In particular, it is interesting to consider when fixing $\mathrm{H}$ or $\mathrm{K}$ alone is sufficient to bring about efficiency.

A general statement follows from examination of (2). Equation (2i) reduces to (1i) (efficiency) iff (6a) holds. So when (6a) holds, even if (6b) is violated, fixing $\mathrm{H}=\mathrm{H}^{*}$ will result in full efficiency. The reason is that then the worker maximizes only with respect to $K$ and the solution to (2i), given $\mathrm{H}=\mathrm{H}^{*}$ is $\mathrm{K}=\mathrm{K}^{*}$. The reverse is true if $(6 \mathrm{~b})$ holds and (6a) 
does not. Then setting $K=K^{*}$ eliminates ( $2 i$ ) as a first-order condition and the solution to (2ii), given $K=K^{*}$, is $H^{*}$.

Equations ( $6 a$ ) and (6b) always hold for pattern plans. Therefore, there should be no constraints on years of service or investment and effort with pattern plans. One might then argue that mandatory retirement should be less prevalent for workers with pattern plans than for conventional plans. This is not a direct implication, however, because mandatory retirement refers to age rather than to years of service.

Conventional plans satisfy $(6 b)$ but violate $(6 a)$. This implies that only constraints on $\mathrm{K}$ (and not $\mathrm{H}$ ) are required to bring about efficiency. Thus skill levels and effort levels are to be precisely specified for conventional plan workers. As the result, piece rate workers who are allowed to select their effort levels, should not have defined benefit conventional plans.

\section{Extensions of the Model and Additional Issues}

Multiple wage Rates

So far, wages have been constant over the lifetime. One question is, how does generalization to multiperiods with different wage rates in each affect the results? specifically, in a two-period context, the pension can be paid for out of the wages from either period, or from some combination of the two. The result is that no matter how it is done, as long as the worker recognizes that his wages depend upon the pension through the zero profit constraint, or is forced to recognize it by an appropriate shift in the wage function, all is internalized and no inefficiency results. Tilting the ageearnings profile has no effect on behavior. This is easily seen. The worker's problem is now 
(11)

$$
\underset{\mathrm{K}, \mathrm{H}_{1}, \mathrm{H}_{2}}{\operatorname{Max}} \mathrm{W}_{1} \mathrm{H}_{1}+\mathrm{W}_{2} \mathrm{H}_{2}+\mathrm{P}\left(\mathrm{H}_{1}, \mathrm{H}_{2}, \mathrm{~W}_{1}, \mathrm{~W}_{2}\right)-\mathrm{C}(\mathrm{K})-\mathrm{L}\left(\mathrm{H}_{1}, \mathrm{H}_{2}\right)
$$

subject to

$$
\mathrm{W}_{1} \mathrm{H}_{1}+\mathrm{W}_{2} \mathrm{H}_{2}+\mathrm{P}=(\mathrm{V}+\mathrm{K})\left(\mathrm{H}_{1}+\mathrm{H}_{2}\right)
$$

and

$$
\mathrm{w}_{1}=\mathrm{V}+\mathrm{K}-\theta \mathrm{P} / \mathrm{H}_{1}, \quad \mathrm{w}_{2}=\mathrm{V}+\mathrm{K}-(1-\theta) \mathrm{P} / \mathrm{H}_{2} \quad 0 \leq \theta \leq 1 .
$$

First-order conditions are:

(11i)

$$
\frac{\partial}{\partial \mathrm{K}}=\mathrm{H}_{1}-\theta \frac{\partial \mathrm{P}}{\partial \mathrm{K}}+\mathrm{H}_{2}-(1-\theta) \frac{\partial \mathrm{P}}{\partial \mathrm{K}}+\frac{\partial \mathrm{P}}{\partial \mathrm{K}}-\mathrm{C}^{\prime}(\mathrm{K})=0
$$

(11iii)

$$
\begin{aligned}
= & \mathrm{H}_{1}+\mathrm{H}_{2}-\mathrm{C}^{\prime}(\mathrm{K})=0 \\
\frac{\partial}{\partial \mathrm{H}_{1}} & =\mathrm{V}+\mathrm{K}-\theta \frac{\partial \mathrm{P}}{\partial \mathrm{H}_{1}}-(1-\theta) \frac{\partial \mathrm{P}}{\partial \mathrm{H}_{1}}+\frac{\partial \mathrm{P}}{\partial \mathrm{H}_{1}}-\frac{\partial \mathrm{L}}{\partial \mathrm{H}_{1}}=0 \\
& =\mathrm{V}+\mathrm{K}-\frac{\partial \mathrm{L}}{\partial \mathrm{H}_{1}}=0 \\
\frac{\partial}{\partial \mathrm{H}_{2}} & =\mathrm{V}+\mathrm{K}-\frac{\partial \mathrm{P}}{\partial \mathrm{H}_{2}}-(1-\theta) \frac{\partial \mathrm{P}}{\partial \mathrm{H}_{2}}+\frac{\partial \mathrm{P}}{\partial \mathrm{H}_{2}}-\frac{\partial \mathrm{L}}{\partial \mathrm{H}_{2}}=0 \\
& =V+K-\frac{\partial \mathrm{L}}{\partial \mathrm{H}_{2}}-0 .
\end{aligned}
$$

Equations (11i), (11ii), (11iii) are the two-period analogue of (1i) and bring about efficiency. Thus, independent of the division of pension costs, i.e., for any $\theta$, as long as the worker is aware of the competitive firm's response to his pension increase, all is internalized and efficient.

This does not imply that pensions never distort incentives. If the worker's own wage does not adjust to his own pension, but rather to the average pension on which he has only a trivial effect, then inefficiencies can result as they do in the one-period case. More fundamentally, if the "true" wage, including the value of pension accrual and other perks. does not equal marginal product, and if the worker is allowed to choose his hours, then inefficiencies result. But this point, which is analyzed in more detail in 
Lazear [1981], is quite independent of pensions and holds even when all compensation takes the form of a direct money wage.

Corner Solutions:

It is useful to consider some special cases. First, consider the case where the $H$ function, (2i), and the $K$ function, (2ii), do not intersect in the positive quadrant. This can happen either because the $L^{\prime}(H)$ function is too flat, reflecting a very low utility loss associated with foregone additional hours of leisure, or because the $C^{\prime}(K)$ function is too flat, reflecting a very low marginal cost of effort or investment. Under such circumstances, time worked, effort and human capital investment are infinite. It is clear that such a situation cannot occur if for no other reason than that the $I(H)$ function becomes vertical (horizontal in the diagrams) when time worked reaches length of life.

Second, it is possible that the $L(H)$ function is perfectly inelastic at $\mathrm{H}=0$. This means that the worker views work at this firm as so distasteful that he is unwilling to supply even one hour at any price. Then the intersection is at the origin, yielding the corner solution that $\mathrm{H}=0$ and $\mathrm{K}=0$. Third, the worker may view all jobs as identical, in which case the $I(H)$ function is perfectly elastic at $I(H)$ equal to the market wage. This makes the $K$ function a vertical line at (market wage - V). If this lies in the positive quadrant, then equilibrium is at the interior intersection, because the worker's value to this firm is sufficient to bid him away from rivals. In the case where that vertical line lies to the left of the vertical axis, no work occurs, because the worker's marginal product, $v$, at this firm is insufficient to warrant employment given the market price of his services. If that line is coincident with the vertical axis, then all are indifferent 
because his marginal product here is identical to the market wage so neither the worker nor firm has a preference over his work location.

Finally, if $C^{\prime}(K)$ is positive for $K=0$ then a corner solution exists if $I^{\prime}(H)$ is sufficiently steep (flat $K$ function in the diagram) to avoid an intersection in the positive quadrant. The interpretation is that the fixed cost of effort or investment is sufficiently high to discourage any work at this job. The solution is $H=0, K=0$.

Incidentally, when comparing the solution, $\mathrm{K}$ has the interpretation of effort or human capital specific to this firm. Obviously, if a corner solution is reached because, say, $v$ is too low relative to the market wage, investment in human capital and effort at the other firm is still possible.

Maximum Age Restrictions:

A number of plans have a maximum age of starting employment such that workers who start after that age are not entitled to enroliment in the pension plan. This is quite aside from any issues of vesting which depends upon years of service, independent of age. Although no solid explanation of this phenomenon is presented, it is useful to consider the issues.

The fact that firms do not want to put old workers of a given tenure together with young workers of given tenure, suggests that old workers cost more in terms of pension payouts even holding years of service constant. The most obvious reason why this is the case is that a worker who starts at age 59 is likely to retire with fewer years of service than a worker who starts at, say, age 45. If defined benefit plans were set up in a way that subsidized retirees with fewer years of service, then it would be more costly to enroll older workers in a pension plan than younger workers. Elsewhere [Lazear 1982, 1983], I have argued that it is efficient to set up pension plans the actuar- 
ial value of which declines with increased years of service because of incentive and turnover effects. I also find empirical support for this proposition. This story seems to provide an explanation for age restrictions, but there remains the queston, why aren't plans made age- as well as experiencedependent? Such a provision would probably be illegal under the Age Discrimination in Employment Act, but this is a relatively recent constraint and it is not clear why it does not apply to the provision that denies pensions to older new hires.

Individualized Wage-Pension Combinations:

The basic result, that pensions cannot affect behavior if the corresponding wage adjustments are accounted for by the worker, leads to an obvious question: Is the wage set independent of the pension, and if so, why? Why doesn't the firm call out a wage-pension combination such that $W=V+K-$ $P(H, K) / H$ so that the worker is forced to internalize everything and to behave efficiently?

The obvious answer is almost definitional. To do so makes the pension identical to wage payments and the pension might as well be eliminated altogether. The fact that wages and pensions are somewhat independent provides some clue as to why there are pensions in the first place.

If pensions are part of an optimal compensation scheme that attempts to deal with problems of incentives and turnover (as argued in Lazear [1982]), then a pension that is independent of the wage for the individual worker provides the extra degree of freedom necessary to restore efficiency. Simply offering a higher wage does not provide the appropriate incentives because of the contingent nature of pensions on performance. Pension "buyouts" of relatively less productive workers are part of the optimal compensation scheme. 
The same is true if the pension functions as an insurance device, paying more to workers who live longer (or who live to the same age but retire earlier). Reducing the pension while at the same time increasing the wage defeats the usefulness of the pension as an insurance device. Allowing the worker to choose his wage-pension allocation results in the standard adverse selection problem and separating equilibrium issues discussed by Akerlov [1970] and Rothschild and stiglitz [1976].

The exception to this is the rationalization of pensions as a tax-free savings account. 9 If it were performing only this function, then allowing the worker to choose the combination of wage with pension would in no way negate the tax saving effects of a pension and would allow the individual to tailor the compensation to his individual situation. As the result, no rationalization of independent wage-pension provisions is provided by the tax argument. Further, if taxes were the issue, a defined contribution plan would win on almost every count. Yet defined benefit plans are prevalent.

Plans That Are Not Actuarially Fair:

All of the analysis is conducted under the simplifying assumption that $\mathrm{P}(\mathrm{H}, \mathrm{K})$ is some fixed payment rather than some annual flow, which more closely describes most pensions. If risk neutrality is assumed, the fact that some workers may receive less than $P$ while others receive more than $P$ is not essential. What is essential is that the interpretation of a pattern plan as one that has $P$ depend upon years of service in a linear fashion and a conventional plan as one that depends upon some salary average and years of service in a linear fashion is not accurate. Aside from explicit nonlinearities built into the benefit formulas, there are implicit nonlinearities which have to do with when the worker retires. 
For example, in the pattern plan, it is the annual flow of pension benefits, not the expected present value of those benefits that increases at constant rate per year of service. In order for this to cause the present value of pension benefits to increase at a constant rate per year of service additional restrictions having to do with life expectancy, discount factors and rate of accrual are required. In reality, I have shown that the contrary is generally the case (Lazear [1982, 1983]). Beyond a certain number of years of service, the present value of pension benefits actually declines with years of service. A similar statement is true for conventional plans of the defined benefit type as well.

In fact, in the case of conventional plans, the reduction in present value with years of service beyond a certain point may help to restore the efficiency that is lost when workers fail to account appropriately for the relationship between wages and pensions. Since, in the absence of a decline, workers tend to overinvest in human capital, to work too hard, and to put in too many hours and years of service, this decline may actually move the situation toward the first-best solution.

Finally, it has been assumed throughout that the wage never exceeds the worker's marginal product. If it does, as I have suggested elsewhere, then seemingly inefficient pensions may actually bring about efficiency.

\section{Conclusion:}

This paper creates as many questions as answers. The goal is to identify the incentive effects of different pension provisions. In doing so, puzzles arise because many provisions appear to have adverse incentive effects. Although few of the puzzles are solved, some directions for empirical investigation are suggested. In particular, the link between the wage 
relationship and productivity variables bears a special correspondence to the pension plan. For example, one implication is that pattern plans should be coupled with wage functions that reward increased effort more generously than those coupled with conventional plans. Further, the incidence of maximum and minimum hours restrictions in pension plans is predicted, as well as the pattern of hours and effort requirements.

Perhaps more important than the empirical implications of the model is the clarifications of the effects induced by various pension provisions. Many of the effects are subtle in mechanism, although not necessarily in size. Few have been considered in the past and this essay takes a first step toward the understanding of these institutions that often seem either innocuous or arbitrary to the casual observer. 
FOOTNOTES

*Helpful comments by Jerry Hausman, Herman Leonard, Barry Nalebuff, and Sherwin Rosen are gratefully acknowledged.

'Blinder, Gordon and Wise (1978), Burkhauser and Quinn (1981), and Fields and Mitchell (1981) examine the effects on retirement behavior. stiglitz (1982) considers vesting effects as well.

${ }^{2}$ For example, investment in human capital may be more easily observed than changes in the level of effort, because the former may require the use of the firm's resources (e.g., other employees as teachers, . . ).

${ }^{3}$ For example, some emphasize tax breaks enjoyed (Black [1980], Tepper [1981], Merton [1982], Sharpe [1976], -Bulow [1979, 1981] while others emphasize incentive and mobility effects (Miller and Scholes [1981], Lazear $[1979,1982,1983])$

${ }^{4}$ The exception is the split in benefit formula between white and blue collar workers.

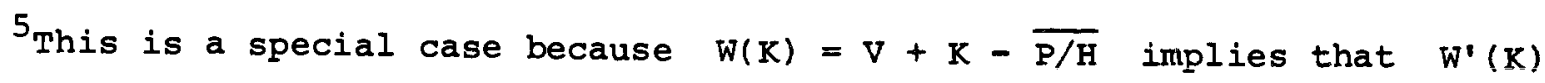
= 1. Additional distortions and offsets can be introduced by choosing other $W(K)$ functions. But unless the general condition that $W(K, H) \equiv V+K-P(K, H) / H$ holds, the deviation from first best remains. Only then can the firm break even and have conditions $(2 i)$ and $(2 i i)$ reduce to $(1 i)$ and (1ii).

${ }^{6}$ In order to achieve an interior solution, it must be the case that the $K$ function is flatter than the $H$ function, or that the disutility of labor hours (i.e., the value of leisure) rises more rapidly than the cost of additional human capital or effort. Suppose it did not. Then the solution would be to continue to invest in $\mathrm{K}$ and keep working more and more hours. Eventually, $H$ approaches maximum feasible hours, so $L^{\prime}(H)$ must become 
infinite, guaranteeing an interior solution.

7 This ignores differences that result from consideration of the reasons for pensions in the first place. This set of predictions is most consistent with the view that a pension serves as a tax-free savings account, but neglects any explanation for pensions having to do with incentives or separation efficiency.

${ }^{8}$ Asch explores this mechanism both at the theoretical level and empirically.

${ }^{9}$ See Miller and Scholes (1982), Bulow (1979, 1981), Black (1980), Tepper (1981), Sharpe (1976), Merton (1982) for discussions. 
REFERENCES

Akerlov, George, "The Market for 'Lemons': Quality Uncertainty and the Market Mechanism," Quarterly Journal of Economics 84 (August 1970): 488-500.

Asch, Beth, "Pensions and Self Selection," Mimeographed. University of Chicago, 1983.

Black, F., "The Tax Consequences of Long-Run Pension Policy," Financial Analysts Journal (July-August 1980): 3-10.

Blinder, A., Gordon, R., and Wise, David, "Market Wages, Reservation Wages and Retirement Decisions," Princeton University, 1978.

Bulow, Jeremy, "Analysis of Pension Funding under ERISA," NBER Working Paper \#402, November 1979.

Bulow, Jeremy, "What Are Corporate Pension Liabilities?" Stanford University Working Paper, July 1981.

Burkhauser, Richard, and J. Quinn, "The Effect of Pension Plans on the Pattern of Iife Cycle Consumption," 1981.

Fields, Gary, and Mitchell, Olivia, "Pensions and Optimal Retirement Behavior," NYSSILR WP \#27 (March 1981).

Lazear, Edward P., "Why Is There Mandatory Retirement?" Journal of Political Economy 87 (December 1979): 1261-64.

Lazear, Edward P., "Agency, Earnings Profiles, Productivity and Hours Restrictions," American Economic Review 71 (September 1981), 606-20. Lazear, Edward P., "Pensions as Severance Pay," NBER Conference Volume on Pensions, forthcoming, 1983.

Lazear, Edward P., "Severance Pay, Pensions, and Efficient Mobility," NBER Working Paper \#854, February 1982. 
Miller, Merton, and Scholes, Myron, "Executive Compensation, Taxes and Incentives," University of Chicago, October 1979.

Merton, Robert C., "On Consumption-Indexed Public Pension Plans," NBER Working Paper \#910, June 1982.

Rothschilä, Michael, and Stiglitz, Joseph E., "Equilibrium in Competitive Insurance Markets: An Essay on the Economics of Imperfect Information," quarterly Journal of Economics 90 (November 1976): 629-49.

Salop, Joanne, and Salop, Steven, "Self-Selection and Turnover in the Labor Market," Quarterly Journal of Economics 90 (November 1976): 619-27.

Sharpe, W., "Corporate Pension Funding Policy," Journal of Financial Economics 3 (June 1976):

Stiglitz, George, "An Economic Analysis of Labor Turnover," Working Paper \#53, The Economics Series, Institute for Mathematical Studies in the Social Sciences, Stanford University, 1975.

Tepper, I., "Taxation and Corporate Pension Policy," Journal of Finance 36 - (March 1981). 


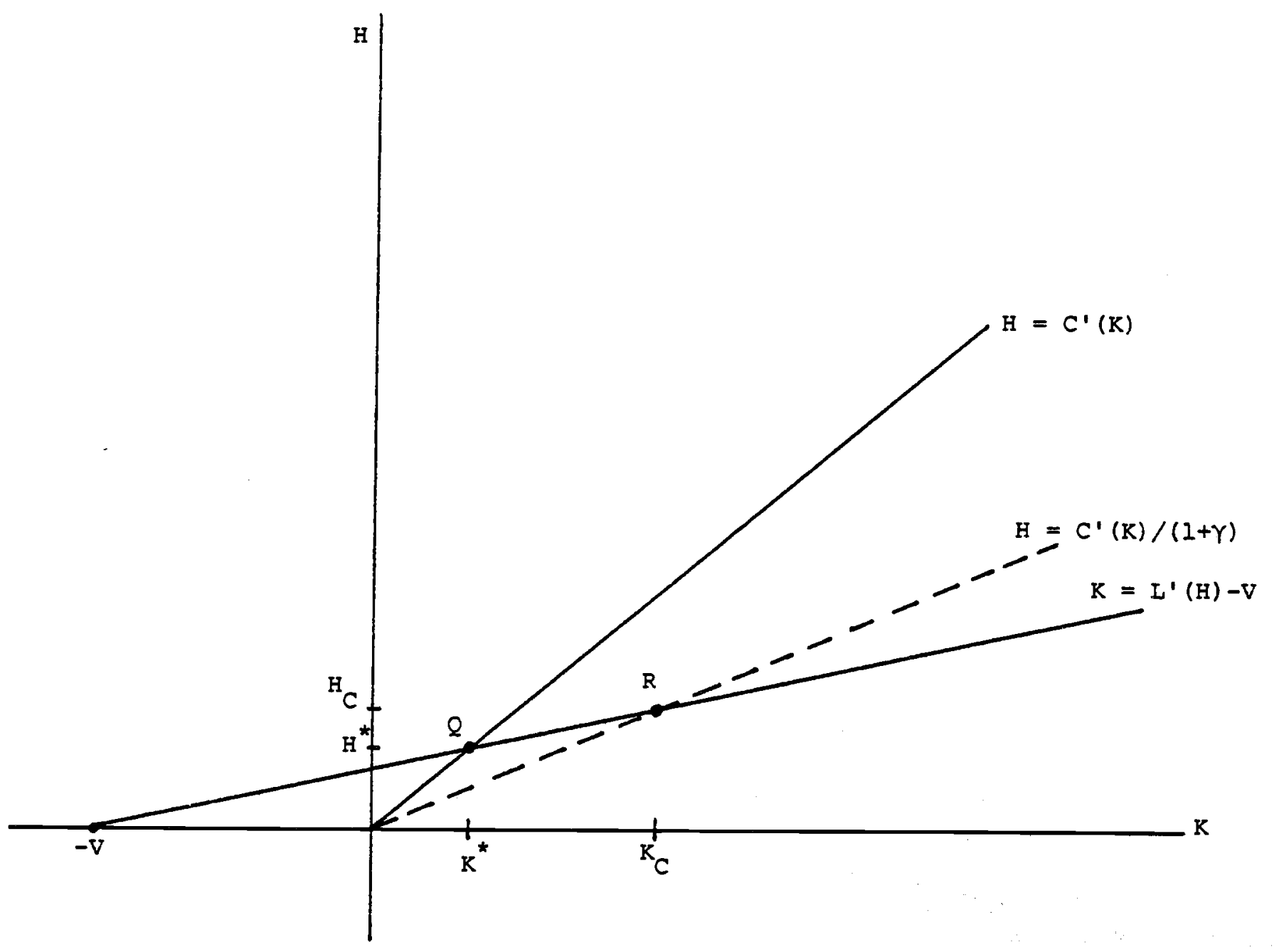

Figure 1 


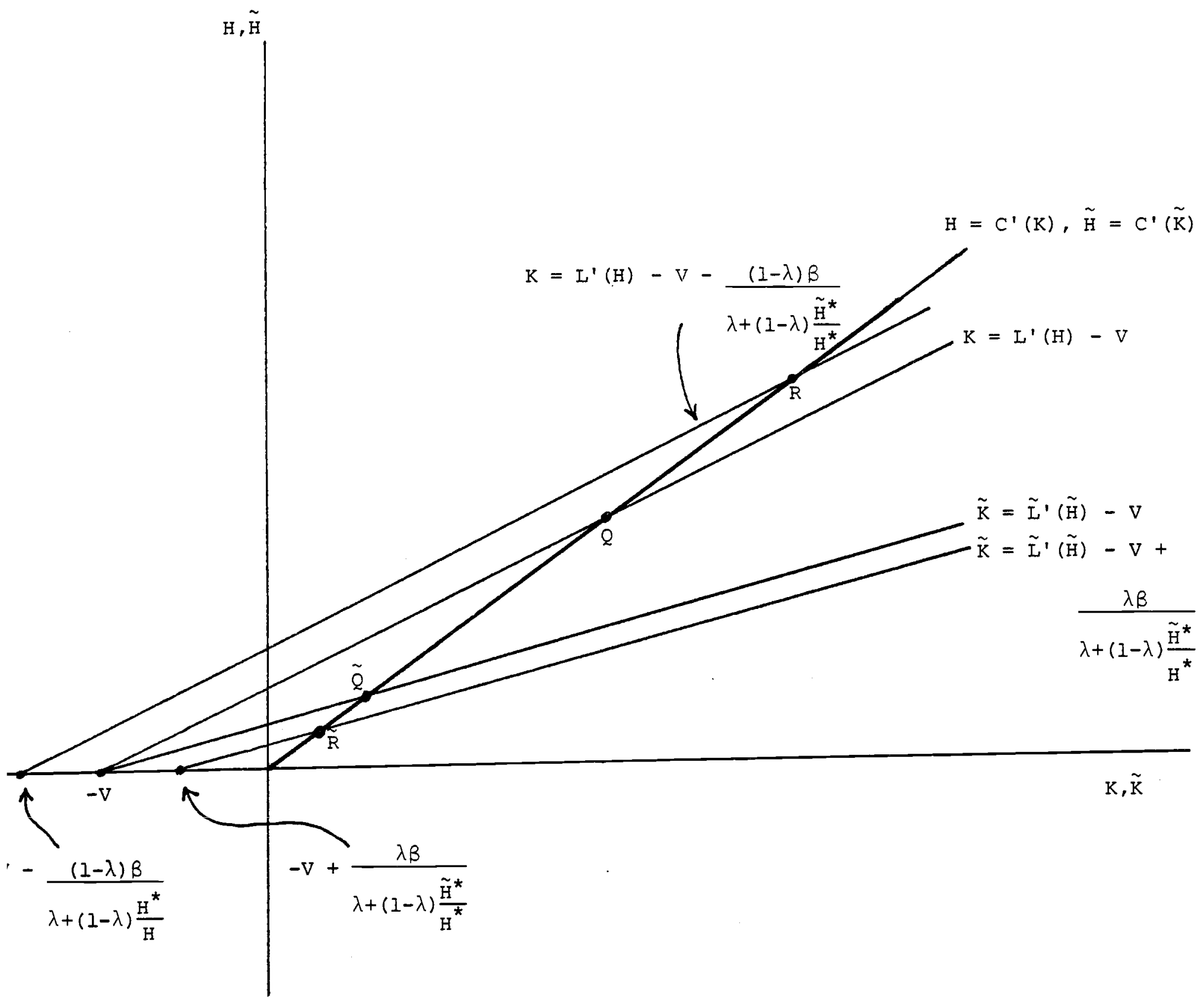

Figure 2 


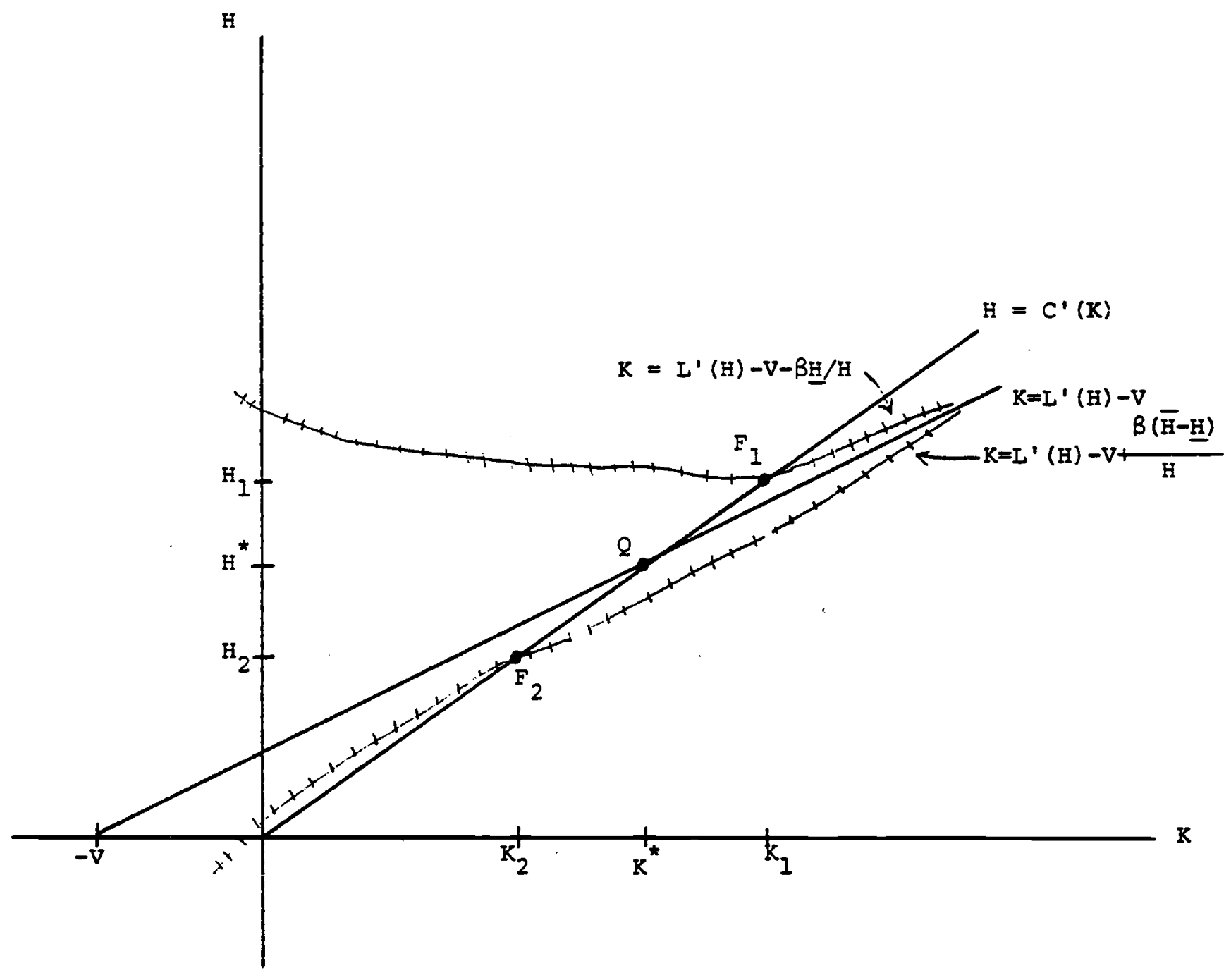

Figure 3 


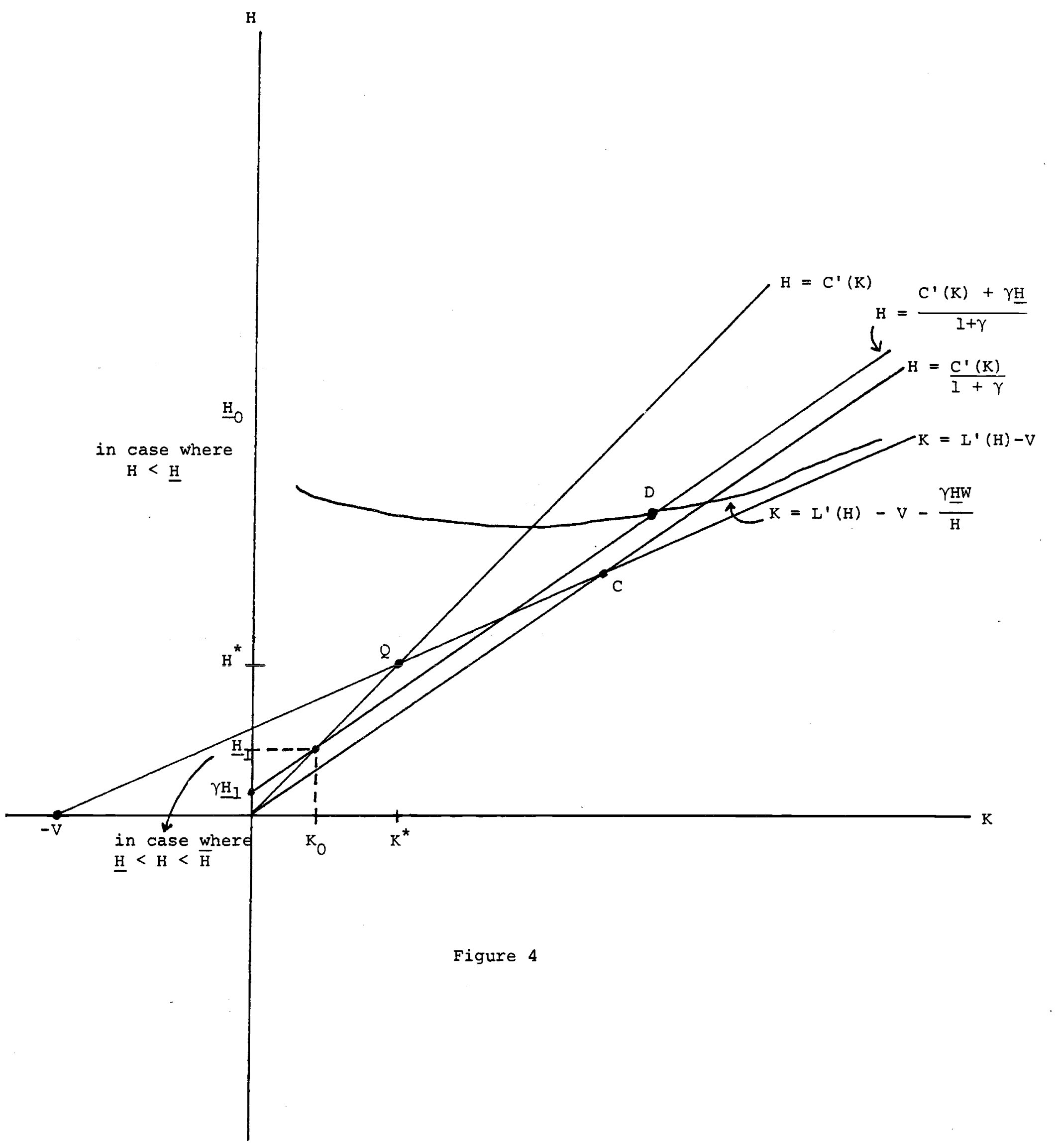




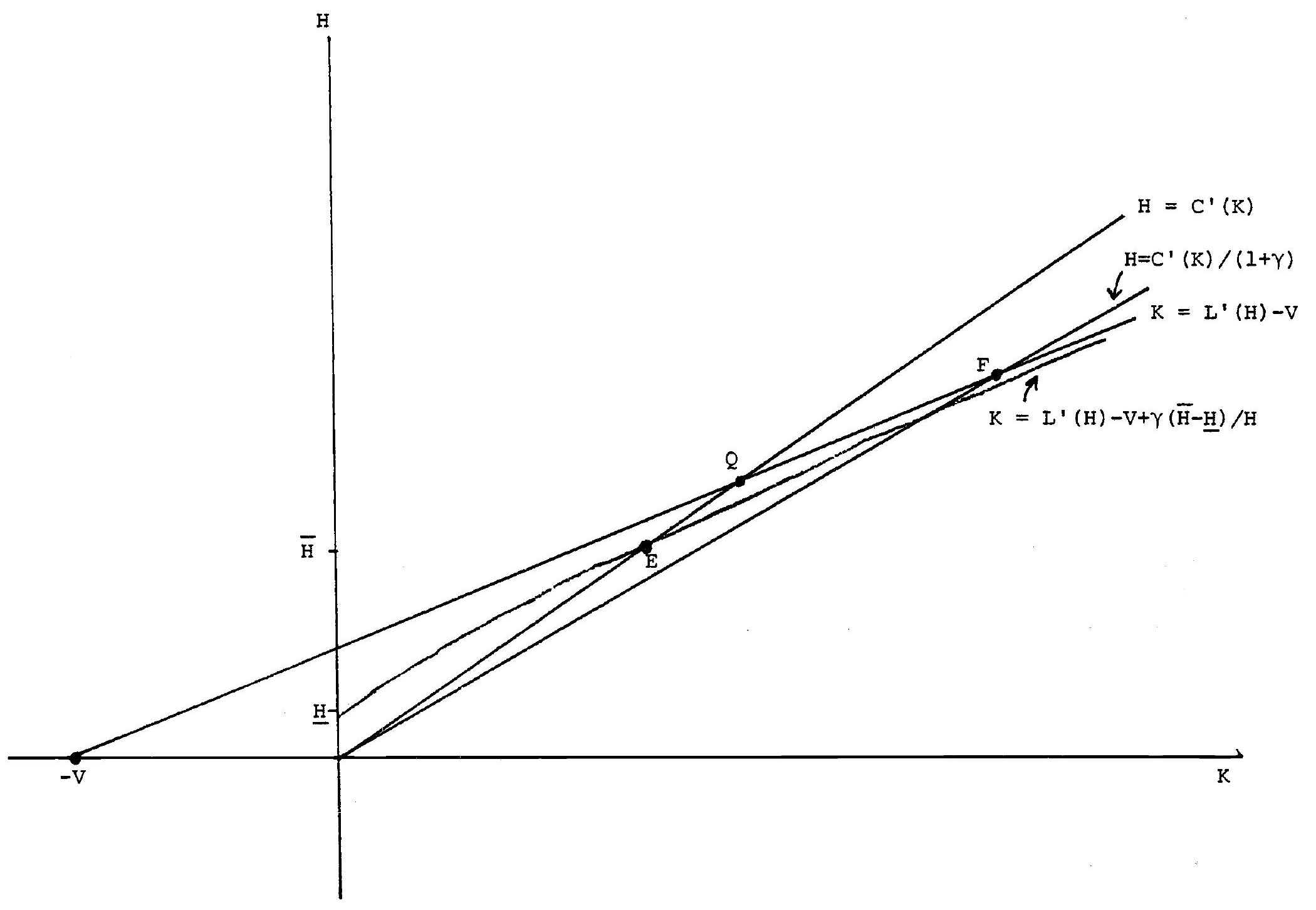

Figure 5 